\title{
Significados, possibilidades e impasses da comunicação intercultural
}
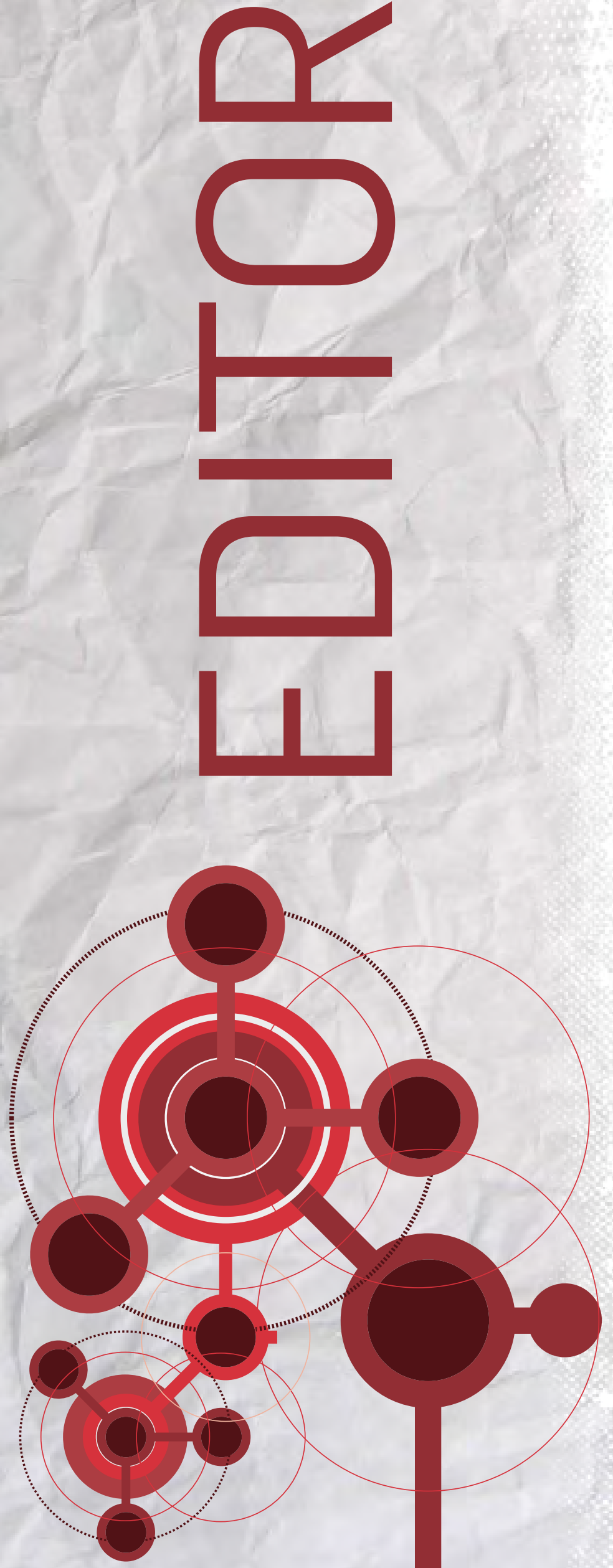

- ratar das relações interculturais e multiculturais é uma das competências mais difíceis na sociedade contemporânea. Desde sempre o homem buscou descobrir lugares, objetos e pessoas e, nesse intento, as mais variadas características culturais passaram a permear o mundo. Em pleno século XXI, as condições para que as interações humanas se deem com mais facilidade $e$ instantaneidade foi facilitada pelos avanços da tecnologia, pelas correntes econômicas, pelas novas lógicas de pensar o mundo e a vida. Portanto, estamos frente a um caleidoscópio de culturas, crenças, tradições, ritos, mitos, histórias que se mesclam e permiteminfinitas formas de conivência, como também de conflito.

Diante desta realidade, é fácil entender como a comunicação, enquanto processo de significados, é essencial para que ocorram os relacionamentos entre culturas. Nos últimos anos, temos vivido intensamente a realidade multicultural, graças à queda de fronteiras políticas e geográficas, como aconteceu, por exemplo, com a União Europeia, onde hoje os cidadãos cruzam livremente as fronteiras entre os países membros. Mas, por outro lado, também temos assistido aos ataques terroristas, à chegada de barcos que transportam imigrantes ilegais para outros países, à homofobia e a outras situações nas quais vemos que a intransigência e 0 preconceito das pessoas têm levado a comportamentos extremistas que mais causam danos que benefícios. Desta feita, surgem algumas questões. Como as diferenças culturais estão impactando (positiva e negativamente) a vida das pessoas? E, por consequência, as diferenças culturais estão afetando também as relações nas organizações?

Olhando essas formas de acordos e desacordos que ocorrem diariamente, seja no cenário nacional como no global, a presente edição da revista Organicom trata de explorar os significados, as possibilidades e os impasses da comunicação intercultural. Tema 
mais que contemporâneo, a relação da comunicação com a interculturalidade é apresentada por um conjunto de textos de especialistas internacionais e nacionais que abordam a temática por meio de várias facetas.

Feitaa convocaçãoàcomunidadeacadêmico-científica eaos profissionais das áreas de comunicação,sociologia, educaçãoe outras, para enviarem seus estudos e suas pesquisas sobre esses campos e suas interfaces, obtivemos um retorno bastante expressivo, uma vez que a temática não tem sido explorada como deveria ser pelos comunicadores no Brasil. Recebemos aproximadamente quarenta textos, dos quais, segundo os critérios da revista, 21 foram aprovados por um comitê avaliador, de acordo com o sistema de peer-review. 0 dossiê temático, além da entrevista com Krishnamurthy Sriramesh, conta com onze artigos na seção específica a ele destinada e outros três na seção de Pesquisa, aos quais se acrescentam quatro das cinco resenhas.

"Significados, possibilidades e impasses da comunicação intercultural" foi o título que demos ao dossiê desta edição, após uma longa conversa com o Prof. Dr. Krishnamurthy Sriramesh. Hoje, esse renomado pesquisador é uma das mais importantes referências na área das relações públicas globais e da interculturalidade, tendo produzido quase uma dezena de livros dedicados a essas temáticas. Sua própria biografia já demonstra sua trajetória multicultural. Nasceu na Índia, realizou os estudos de mestrado e doutorado nos Estados Unidos e trabalhou em quatro continentes. Sua visão de mundo global é fruto de sua vida de globetrotter, de "eterno viajante", o que permitiu desenvolver ainda mais a sua sensibilidade cultural. Sobre isso ele afirma: "O mais importante para mim foi a mudança que as outras culturas me propiciaram. Na realidade foi o aprimoramento da inteligência emocional. Acredito que a inteligência emocional é pré-requisito para alguém se tornar um comunicador de sucesso no mundo global".

A entrevista do professor Sriramesh à revista Organicomé um presente para todos os leitores. Como já foi mencionado, o campo da intercultralidade tem sido pouco explorado pelos comunicadores, mesmo conscientes de que não há comunicação sem identificar os processos culturais evice-versa. Concordamos que cultura e comunicação são os dois lados de uma mesma moeda. Assim sendo, a conversa com o renomado professor traz novos olhares, bem como um conselho para que os comunicadores brasileiros comecem a desenvolver mais pesquisas na conexão entre esses dois campos: comunicação e cultura.

Em primeiro lugar, é preciso que fique clara a importância desses dois campos de estudo no contexto atual, uma vez que já vivemos em um mundo globalizado em que os contatos são cada vez mais rápidos, mas nem sempre a interação é o resultado deles. As faculdades de comunicação devem incorporar a disciplina de comunicação intercultural, uma vez que em futuro próximo as sociedades serão cada vez mais multiculturais e as relações interculturais serão mais frequentes. Como afirmou Sriramesh na sua entrevista, "a expansão das tecnologias de comunicação e informação, a queda das barreiras comerciais e o reconhecimento quase universal de problemas como o terrorismo e a contaminação do meio ambiente têm propiciado 0 incremento das interações entre os três setores da sociedade no mundo todo".

Com a entrevista de Sriramesh, concluímos que cada dia somos mais conscientes da nossa própria complexidade social e que começamos a entender a complexidade social alheia. Estamos no momento justo para refletir e repensar para negociar muito do que sabemos (e não sabemos!). Terminamos por aqui com uma pergunta: qual deveria ser o olhar de um comunicador intercultural? Com certeza a resposta nos levará a produzir outra edição da nossa revista. Porém, conseguimos entender que esse olhar não pode ser nem parcial e nem inconsequente.

Abre esta edição de Organicom a seção Espaço Aberto, que traz artigos com assuntos inovadores e também com enfoques contemporâneos. Trazemos dois textos que mostram estudos voltados a um novo olhar para a área da comunicação e das 
relações públicas. Em "Impresso versus digital: uma reflexão sobre a transição do meio impresso", Maria Aparecida Ferrari e Carmen Valéria de Andrade Barreto abordam a transição do meio impresso para o digital entre jovens universitários e líderes de opinião da área editorial e da comunicação. 0 objetivo é entender como as pessoas estão se relacionando (ou não) e como percebem essa transição da plataforma impressa para a digital. Os resultados sugerem que o livro impresso coexistirá com 0 digital de forma harmoniosa pelo menos nas próximas décadas, uma vez que ainda estamos longe do tempo em que o digital prevalecerá sobre o impresso e será a única opção de plataforma de leitura e disponibilização de conteúdo.

Em seguida, o pesquisador argentino Gabriel Sadi nos brinda com o texto "En torno al objeto de estudio y las implicancias sociales de las relaciones públicas", em que trata de refletir sobre a construção identitária das relações públicas e seu objeto de estudo e papéis sociais que levam ao exercício profissional. Sadi utiliza a corrente crítica das relações públicas e aponta que os papéis sociais foram historicamente postos de lado pela literatura predominante. Não obstante, a atenção das associações globais para esse aspecto está crescendo e tal enfoque pode impactar em uma maior legitimidade pública da profissão.

A seção do Dossiê traz onze textos com estudos de diferentes áreas do conhecimento e que apontam a força da interculturalidade nas relações sociais. 0 primeiro artigo é de autoria de duas pesquisadoras espanholas da área da psicopedagogia, Assumpta Aneas Alvarez e Ruth Vilà Baños, que discutem a "Confianza interpersonal y competencia intercultural en los equipos de trabajo virtuales". O texto apresenta, dentro da perspectiva intercultural, duas dimensões da confiança interpessoal, representadas pelos fatores cognitivos e pelos fatores afetivos. As autoras concluem que as culturas se diferenciam na maneira de ganhar e de perder a confiança nas relações virtuais, considerando elementos como a influência dos estereótipos e preconceitos culturais sobre as expectativas com respeito ao outro, a atitude de sensibilidade intercultural com respeito à diferença cultural, a conciliação de objetivos individuais e grupais, a tolerância à incerteza, a gestão do tempo, as fontes de reconhecimento pessoal e social desde a perspectiva cultural, o sentido da honradez, o valor do contexto, o universalismo e o particularismo no trabalho virtual.

Em seguida, Mónica Ayala Soliz e Fábio Radigonda Serrato comparecem com o texto "As expectativas dos imigrantes bolivianos na cidade de São Paulo: reflexões sobre a comunicação intercultural", no qual apresentam uma pesquisa realizada com bolivianos na cidade de São Paulo. Esse artigo procura analisar as expectativas econômicas, sociais e legais desses imigrantes, verificar como se dá a comunicação intercultural nos relacionamentos que eles estabelecem e identificar as dificuldades e facilidades de adaptação na cidade. Utilizando técnicas quantitativa e qualitativa, as conclusões reforçam que as estratégias de comunicação intercultural podem influenciar nas expectativas dos bolivianos sobre a cidade, além de contribuir para a integração dos referidos imigrantes.

"Interculturalidade e comunicação nas organizações: reflexões antropológicas e notas para uma agenda de pesquisas" é 0 texto preparado por Pedro Jaime de Coelho Junior, que trabalha com a temática de cultura na sociedade. 0 autor propõe uma reflexão sobre o debate antropológico contemporâneo em torno do conceito de cultura, assim como da ideia de diversidade. 0 propósito dessa reflexão é extrair, da mirada da antropologia para essas questões, contribuições que possam fertilizar a pesquisa sobre interculturalidade e comunicação nas organizações.

Passando ao âmbito organizacional, Daniela Motta Romeiro Khauaja, no artigo "Gestão de marcas na estratégia de internacionalização de empresas: um estudo exploratório no Banco Itaú", foca o caso do dessa instituição, que hoje já é uma marca global, aquela que, segundo Nigel Hollis, "transcende suas origens geográficas e culturais para desenvolver forte 
relacionamento com consumidores em diferentes países e com diferentes culturas". Daniela, em seu artigo, cita David Aaker e Erik Joachimsthaler, autores para os quais desenvolver marcas globais sólidas inclui "utilizar estruturas organizacionais, processos e culturas para alocar globalmente os recursos de construção da marca criando sinergias globais, além de desenvolver uma estratégia global de marca que coordene e potencialize as estratégias de cada país". Mas os autores também apontam para "o desafio de encontrar um equilíbrio entre potencializar a marca globalmente e respeitar as diferenças locais, tema recorrente na discussão sobre o marketing global".

Leila Gasparindo e Ana Cristina da Costa Piletti Grohs discutem as características da cultura nacional e sua influência nos códigos de ética das empresas. No artigo "Traços da cultura nacional e da cultura de inovação: uma análise dos códigos de ética de empresas brasileiras", as autoras tratam de apresentar uma pesquisa exploratória a partir de estudo bibliográfico e de análise documental dos códigos de éticas de três empresas brasileiras. 0 resultado aponta que os códigos de ética podem contribuir para a formação da cultura de inovação e que as empresas que mais incentivam os aspectos da cultura de inovação são também aquelas com melhor colocação no ranking Forbes.

Maria Ivete Trevisan Fossá, com o texto "Possibilidades de análise da diversidade cultural pelas instâncias mítica, socialhistórica, institucional, organizacional, grupal, individual e pulsional", traz ao debate uma reflexão sobre as organizações concebidas como um sistema cultural, simbólico e imaginário, lugar onde se entrecruzam desejos individuais e coletivos, projetos conscientes e inconscientes. Este estudo mostra as duas principais dimensões do imaginário - enganadora e motora - e as possibilidades de análise da cultura organizacional levando em consideração as instâncias mítica, social-histórica, institucional, organizacional, grupal, individual e pulsional, que são trabalhadas pelo pensador francês Eugène Enriquez.

Com o título "Grandes empresas e interculturalidade: importância do profissional de relações públicas no ambiente digital", Fabiana Grieco Cabral de Mello Vetritti e Rafael Vergili discorrem sobre a internet e a alteração das formas de relacionamento entre grandes empresas e públicos de interesse. Com o aumento do acesso mundial à rede, quebra-se a barreira do tempo e do espaço, gerando integrações e apontamentos de diversas culturas nas diretrizes comunicacionais das organizações brasileiras, fatos que estão ligados à interculturalidade. Os autores afirmam que os profissionais de relações públicas - teoricamente formados para promover diálogo e realinhamento de estratégias - têm baixa inserção nas atividades relativas ao ambiente digital, como apontam duas pesquisas (quantitativa e qualitativa) apresentadas no artigo.

Usando uma abordagem da área da gestão, Elis Magalhães Santos de Freitas, Merlise Rupolo e Brigitte Renata Bezerra de Oliveira apresentam o texto "O processo de internacionalização de uma empresa do Vale do São Francisco: influência dos agentes externos e das escolhas gerenciais", que analisa as principais características do processo de formação de estratégias internacionais de uma empresa no segmento de fruticultura do Vale do São Francisco, considerando a influência dos agentes externos e das escolhas gerenciais. As autoras evidenciam as associações que ocorrem entre os modelos de internacionalização e o modo pelo qual as dimensões de análise são reforçadas mutuamente.

"A interculturalidade como orientação metodológica e de análise na comunicação organizacional" é a pesquisa apresentada por Viviane Fushimi Veloso e Mitsuru Higushi Yanaze, que fazem uma proposta metodológica embasada no estudo da interface comunicação e tecnologias da informação, pautada em observação, pesquisas e análises, visando à "comunicação excelente" 
por meio das "expectativas compartilhadas". Para os autores, a complexidade do ambiente organizacional aumenta devido às transformações econômicas, sociais e culturais.

Em seguida, Wellington Teixeira Lisboa discute, em "Cenas da diversidade no ambiente empresarial: os atuais fluxos migratórios internacionais para o Brasil e o desafio da interculturalidade", os fluxos de trabalhadores e outros migrantes internacionais no Brasil, desde a transição para o corrente século. Esse movimento desencadeia a recomposição de equipes de funcionários não apenas em corporações multinacionais ou globais atuantes no país, mas também nas empresas nacionais de médio e grande porte que passaram a empregar profissionais estrangeiros. Nesse cenário, essa reflexão focaliza a centralidade da cultura e da comunicação institucionais como vias estratégicas para a promoção do diálogo intercultural no ambiente empresarial.

A linguista Ana Lúcia Magalhães trata, em "Culturas regionais brasileiras em um ambiente corporativo", a questão de como as culturas regionais subsistem e enriquecem o contexto mesmo sob a pressão de equipes multidisciplinares e multirregionais. Isso se deve a uma escala que, embora varie de cultura para cultura, mantém certos valores, tanto instrumentais como objetivados, comuns a todos os membros daquele grupo. A retórica se revela uma ferramenta importante na investigação.

O dossiê propriamente dito finaliza com o texto "Reflexões sobre comunicação nas organizações interculturais em uma perspectiva sustentável", de autoria de Érik Álvaro Fernandes e Marlene Marchiori, que discute, no âmbito das ideias, que as organizaçõessão simultaneamenteagenteseespaços interculturaisque demandamsujeitos em processo de interculturalidade. Nessa dinâmica estão implícitos desafios que requerem a participação dos sujeitos em interação, a qual tem a comunicação como produtora de sentidos na construção de realidades interculturais organizacionais.

Ao concluir essa seção, vale enfatizar os diferentes enfoques que foram utilizados nos textos para tratar da mesma temática: a interculturalidade como processo de mescla por que cada pessoa e cada cultura passam para poder interagir em sociedade. E, também, vale reforçar que a interculturalidade está intimamente vinculada à educação intercultural que permite o espaço de convivência e interdependência das pessoas, de grupos e da sociedade em si mesma.

A seção de Pesquisa apresenta três interessantes estudos que também abordam a questão intercultural de facetas distintas. Seis docentes e pesquisadoras do curso de Relações Públicas, da Universidade Estaual Paulista, de Bauru (SP), apresentam uma metodologia de ensino-aprendizagem que vem proporcionar aos alunos a possibilidade de experimentar e interagir com o mundo real dos negócios. 0 artigo "A interculturalidade no ensino-aprendizagem em relações públicas: contribuições a partir de uma parceria internacional" trata de uma experiência intercultural referente à parceria internacional de ensinoaprendizagem em relações públicas entre a Unesp-Bauru e a Universidade de Sevilha (Espanha). 0 objetivo é refletir sobre a noção de interculturalidade e sua importância na formação em relações públicas, apresentando resultados dessa intervenção acadêmica. As autoras descrevem a parceria, discutem as influências desse processo e sua vivência intercultural.

Em seguida, analisando marcas que têm uma reputação positiva junto aos jovens e esportistas, a pesquisa "Comunicação, redes sociais e desafios da interculturalidade na sociedade contemporânea: casos IAC e Adidas", de autoria de Marcelo da Silva, Katarini Giroldo Miguel e Jéssica de Cássia Rossi discute as proposições da comunicação intercultural para as organizações contemporâneas, em um contexto de sociedade largamente globalizado, que recombina informação e comunicação nas plataformas digitais, manifestando suas alteridades e diferenças culturais. A pesquisa utiliza dois estudos de caso: o primeiro, 
de uma funcionária da empresa IAC, que se envolveu em um comentário racista em uma rede social; o segundo, da marca Adidas. que teve que retirar produtos de circulação após manifestos e acusações de apelo sexual de consumidores brasileiros.

A última pesquisa, "Narrativas, relações públicas e comunicação intercultural: o caso do Brazilian corporate communications day", desenvolvida por Else Lemos Inácio Pereira, Emiliana Pomarico Ribeiro e Carolina Aparecida Temoteo Modesto, aborda a relevância das narrativas como instrumento de atuação no contexto das relações públicas interculturais, por meio de reflexão sobre cultura, multiculturalismo, interculturalidade e o papel das práticas de comunicação organizacional e relações públicas na construção das narrativas sobre o Brasil. Para isso, toma como caso o "Brazilian corporate communications day", iniciativa que a Associação Brasileira de Comunicação Empresarial (Aberje) iniciou em 2010 para promover uma agenda positiva e contemporânea sobre o Brasil, tendo como foco suas metanarrativas e micronarrativas. "O projeto estabelece uma narrativa que expressa o vigor e a qualidade da comunicação empresarial brasileira, o que, numa perspectiva intercultural mais ampla, implica o compromisso com a promoção da diversidade e com a construção de mensagens que favoreçam o entendimento do ambiente brasileiro sob o ponto de vista cultural, social, de negócios e, sobretudo, comunicacional, como escrevem as autoras".

A última seção, de Resenhas, é dedicada a apresentar obras que tratam da relação entre a comunicação e a interculturalidade. Das cinco resenhas, quatro tratam especificamente das questões da cultura e da comunicação. Carolina de Avellar Barbosa Moretti apresenta a obra Culture, leadership, and organizations: the Globe Study of 62 societies, organizada por Robert J. House. $O$ livro, publicado em 2007, continua sendo inovador e está estruturado em três partes: a introdução, os capítulos sobre 25 sociedades estudadas e a parte final com a conclusão, totalizando 1.162 páginas. Essa obra é fundamental para todos que estudam as organizações ao redor do mundo e necessitam conhecer especificidades de cada um dos 25 países estudados, além de destacar as características da cultura e como ela se manifesta no processo de liderança.

Ana Cristina da Costa Piletti Grohs apresenta um resumo do livro Diálogos interculturais: reflexões interdisciplinares e intervenções psicossociais, organizado por Sylvia Duarte Dantas e produzido pelo Instituto de Estudos Avançados da Universidade de São Paulo (IEA-USP). A obra, em formato de e-book, reúne dezessete textos de autores de diferentes áreas do conhecimento, demonstrando que os estudos interculturais são em sua essência construções interdisciplinares e que, como projeto ético, o diálogo intercultural deve ser guiado pela aceitação da alteridade. Os capítulos discutem a identidade e a alteridade, perpassando questões étnicas, religiosas, socioeconômicas, indígenas, literárias, migratórias, de saúde mental e pública e até intervenções psicossociais realizadas com estrangeiros.

A obra Gestão em ambientes multiculturais, publicada em 2013, de autoria de Letícia Fantinato Menegon, Germano Glufke Reis e Gilberto Sarfati, é apresentada por Fabiana Colturato Aidar. 0 conteúdo do livro possibilita uma visão didática e panorâmica de como atuar nos contextos multiculturais, sendo aplicável a estudantes e profissionais das áreas de administração, recursos humanos e comunicação. Dividido em nove capítulos curtos, o livro descreve, logo na introdução, as características básicas de um executivo global.

Maura Padula analisa o livro Guia de migrações transnacionais e diversidade cultural para os comunicadores: migrantes no Brasil, de Denise Cogo e Maria Badet, publicado em 2013. 0 objetivo da obra, disponível em formato de e-book, é contribuir com o trabalho de comunicadores na cobertura das novas realidades migratórias. 0 guia destaca, também, o fluxo de migração dos haitianos para o Brasil, a partir da concessão dos vistos humanitários; os incrementos da presença latino-americana - 
principalmente de bolivianos - e africana; o aumento da comunidade asiática; o crescimento da presença de refugiados. $\mathrm{E}$ ainda oferece dados referentes aos atrativos que europeus e norte-americanos veem no país.

Finalmente, Maria Aparecida Ferrari comenta a obra "Comunicação empresarial: alinhando teoria e prática", de Wilson Bueno, publicada em 2014. Segundo o autor, as práticas profissionais têm gerado uma comunicação empresarial sem identidade, norteada por uma visão imediatista, sem compromisso com a ética e com os preceitos teóricos da área e que resulta na negação da complexidade e da pluralidade organizacional. Dividida em três partes, a primeira é dedicada à reflexão do âmbito teórico da comunicação empresarial; a segunda apresenta as boas práticas de comunicação e traz casos para ilustrá-las, como a questão da diversidade corporativa e a gestão de crises; e a última parte traça um panorama da produção científica no Brasil, analisa sua evolução e a qualidade dos estudos conduzidos no campo comunicacional.

Agradecemos a todos os pesquisadores que enviaram seus estudos para a nossa revista Organicom, assim como a toda a equipe do comitê editorial e aos pareceristas. Um especial agradecimento ao professor Krishnamurthy Sriramesh, por sua disponibilidade e presteza durante a nossa conversa. Acreditamos que o dossiê desta edição é único na área da comunicação organizacional e relações públicas no Brasil, à medida que, até o momento, não registramos um compêndio de textos como esse que aqui apresentamos. Sem dúvida, o material reflete a trama que envolve os processos de comunicação e de interculturalidade. Somos eternos aprendizes, ávidos por saber mais e cada vez mais rápido. Cabe a nós, professores, pesquisadores, alunos e profissionais, seguir sempre no caminho das descobertas que permitem o compartilhamento do conhecimento. 